\title{
Comparison of ultrasound guided brachial plexus blockage with general anesthesia and cost analysis
}

\author{
Abdullah Kahraman ${ }^{1^{*}}$, Nureddin Yüzkat ${ }^{2}$, Muhammed Bilal Çeğin ${ }^{2}$, Volkan Baydi $^{2}$ \\ ${ }^{1}$ Department of Anestesiology, Van State Education and Research Hospital, Health Science University, Ministry of \\ Health, Van, Turkey \\ ${ }^{2}$ Department of Anestesiology and Reanimation, Dursun Odabas Medical Center, Yuzuncu Yil University, Van, Turkey
}

\begin{abstract}
Peripheral block practices are becoming the primary choice of anaesthesiologists among anaesthesia practices. In peripheral nerve block practices, anaesthesia is limited to the area in which nerves innervate and the cardiopulmonary system is minimally affected. Besides these, vigilance of the patient is another advantage. In this study, we aimed to make in patients who underwent upper extremity surgery, comparisons between the brachial plexus block and general anaesthesia in terms of patient and surgeon satisfaction, postoperative complications and cost analysis.
\end{abstract}

Key Words: Analgesic requirement, brachial plexus, general anaesthesia, ultrasound

\section{Introduction}

Regional anaesthesia is performed with local anaesthetic injection in the peripheral nerves, periphery of ganglia and the plexus, intrathecal and epidural space to maintain anaesthesia and analgesia in a specific area (1). Brachial plexus block (BPB), was performed for the first time in 1884 by Halsted with blind techniques. Regional anaesthesia practices have thoroughly been changed with the use of ultrasound in recent years, with better needles, catheter systems and monitoring methods (2). All of these advances made multiple anaesthesia options to the patient possible.

In the choice of anaesthetic technique, besides the request of the patient and experience of the physician, cost is an important factor that will affect the preference $(3,4)$. When significant increases in health expenses across the globe in recent years are considered, the development of methods to reduce costs is crucial.

In this study, we aimed to determine which method was superior; general anaesthesia versus brachial plexus block anaesthesia in patients undergoing upper extremity surgery in terms of anaesthesia quality, postoperative complications, patient comfort, patient satisfaction, and cost as in the contemporary world where economical use of resources have become more and more important.

\section{Material and methods}

This study was taken up after local ethics committee approval (12.11.2014 date and No. 2). Among the cases scheduled for upper extremity surgery, 60 patients who are in ASA I-II groups according to the classifications of the American Society of Anaesthetists (ASA), between the ages of 18-65, for whom emergency or elective, singlesided hand, forearm or arm surgery with brachial plexus blockade or general aesthesia planned were included in the study. Written-verbal permissions were obtained by providing information to each case about the preoperative practice. Patients who did not want to be involved in the study, ASA IIIIV patients, those who used drugs with sedative hypnotic effect, those with whom cooperation couldn't be established, those who had local infection, sepsis, coagulation disorder in the initiative areas or drug allergy history were excluded from the study.

Two cases were separated into two groups by application order. USG guided peripheral nerve block was done in the first group (BPB group). The other group underwent general anaesthesia (GA group).

After both group cases were taken to the operation room, routine monitoring (ECG, peripheral oxygen saturation and non-invasive blood pressure measurement) was done. The 
appropriate IV fluid was given through vascular access.

In $\mathrm{BPB}$ group, after the patients were placed in supine position, block preparations were made. Levobupivacaine $(15 \mathrm{ml}$ of $5 \%$ ) and $5 \mathrm{ml}$ of $0.9 \%$ isotonic mixture and $15 \mathrm{ml}$ solution for interscalene block and $50 \mathrm{~mm} 22 \mathrm{G}$ (Stimuplex ${ }^{\circledR}$ Ultra, Braun, Germany) needle, $20 \mathrm{ml}$ solution and $50 \mathrm{~mm} 22 \mathrm{G}$ needle, for supraclavicular block, injector with $25 \mathrm{ml}$ solution and $100 \mathrm{~mm} 22 \mathrm{G}$ needle for infraclavicular block were used. Ultrasound (US) (Esaote ${ }^{\circledR}$ MyLab 5, Italy) guidance was provided by using linear probe. Complying with asepsis-antisepsis conditions, local anaesthetic mixture under the guidance of US was applied with intermittent aspiration, as no bleeding was observed. After the distribution of the drug was observed, it was injected into the plexus and peripheral cords.

After preoxygenation, $1 \mathrm{mg}$ midazolam followed by $2 \mathrm{mcg} / \mathrm{kg}$ fentanyl, $2 \mathrm{mg} / \mathrm{kg}$ propofol, 0,1 $\mathrm{mg} / \mathrm{kg}$ vecuronium were applied in induction with sedation purposes to patients who would undergo general anaesthesia. The patient ventilated by mask for about 3 minutes, was connected to anaesthesia device after intubation with laryngoscope in convenient sizes for the patient and intubation tube. The depth of anaesthesia was monitored during the operation with BIS (Bispectral index) monitorization. The maintenance of anaesthesia was provided with sevoflurane by keeping the BIS value between 40 and 65. Throughout the surgery, every half an hour $0.5 \mathrm{mcg} / \mathrm{kg}$ fentanyl and $0.03 \mathrm{mg} / \mathrm{kg}$ vecuronium were intravenously applied. $50 \mathrm{mg}$ tramadol was given to the patients before they woke up from anaesthesia. At the end of the operation, $0,1 \mathrm{mg} / \mathrm{kg}$ atropine and $0,3 \mathrm{mg} / \mathrm{kg}$ neostigmine were applied to all patients without contraindications.
In both anaesthesia methods, all medicine and consumables used for the patients in the perioperative phase were recorded. BIS monitorization done in general anaesthesia given patients was not included in the cost as it is used for standardization of the practice.

Right after the operation was regarded as the postoperative 0th minute. Postoperative 0th minute patients' Visual Pain Scores (VAS) and patient satisfaction scales were evaluated and recorded. The patient satisfaction scale was evaluated as; not satisfied 0 , less satisfied 1, and satisfied 2. Visual pain score was evaluated as; 0-2 no pain, 3-4 mild pain, 5-6 moderate pain, 7-8 severe pain, 9-10 excruciating pain. No analgesia was given to the patients in the postoperative period until the pain was first felt. VAS value when the pain was first felt and patient satisfaction scales were recorded then evaluated.

For surgeon satisfaction scale, surgeons were postoperatively asked whether they were content with the operations in which they made the blocks. The patient satisfaction scale was evaluated as; not satisfied 0 , less satisfied 1 , and satisfied 2. In the postoperative period, until the patients were discharged, any evidence of infection and whether there were any patient complaints or not were closely followed up. The medicine used in our cost analysis and their costs were shown in Table 1. Medicine prices were based on the prices hospital pharmacy purchased them. For consumables, the prices paid by social security institution according to health practices statement were taken into consideration.

Statistical analysis: Descriptive statistics for constant variables among emphasized features were expressed as; Average, Standard Deviation, Minimum and Maximum values, Categorical variables were expressed as figures and percentages. In terms of constant variables one-

Table 1. Price table of the medicine and equipment used in the study

\begin{tabular}{lclc}
\hline The medicine and equipment used & Price/ TL & The medicine and equipment used & Price/ TL \\
\hline Midazolam $5 \mathrm{mg} / 5 \mathrm{~mL}$ & 0.90 & USG gel (Cathejell) & 3.3 \\
Fentanyl $500 \mathrm{mg} / 10 \mathrm{~mL}$ & 2.88 & Sterile drape & 4 \\
Vecuronium $10 \mathrm{mg}$ & 5.35 & Peripheral pin & 20 \\
Sevoflurane & 172 & Breathing circuit & 40 \\
Bupivacaine $100 \mathrm{mg} / 20 \mathrm{~mL}$ & 3.68 & Endotracheal tube & 1 \\
Isotonic $1000 \mathrm{~mL}$ & 2.3 & Bacteria filter & 5 \\
Contramal iv $100 \mathrm{mg}$ & 1.26 & $\mathrm{O}_{2}$ mask & 1.75 \\
Atropine $0.5 \mathrm{mg}$ & 0.16 & $\mathrm{H}_{2}$ receptor blocker & 0.16 \\
Neostigmine $0.5 \mathrm{mg}$ & 0.28 & Propofol $200 \mathrm{mg} / 20 \mathrm{~mL}$ & 1.36 \\
Metoclopramide amp. & 0.78 & & \\
\hline
\end{tabular}

East J Med Volume:22, Number:1, January-March/2017 
sided variation analysis was made in group comparisons. Chi-square test was made in order to define the relation between groups and categorical variables. Statistical significance level in calculations was taken as 5\%, and SPSS statistics package program was used for calculations.

\section{Results}

No statistical difference was seen when the groups were compared in terms of age, sex, weight, duration of operation, ASA scores and types of surgery (Table 2).

When the two groups were compared in terms of cost, BPB group was found to be significantly lower than GA Group ( $<<0.05)$ (Table 3).

In BPB group, the first analgesic need was found to be later, in terms of VAS values and patient satisfaction BPB was found to be superior $(\mathrm{p}<0.05)$ (Table 4).

No difference was found between the groups in terms of surgeon satisfaction and hospitalization duration (Table 5).
Hemodynamic complications were seen in 11 patients in GA Group, while none were seen in BPB group. In BPB Group 1 patient had intraoperative agitation, 1 patient had mild intraoperative pain. However, the operation was completed without any problems without the need for any additional medication (Table 6).

\section{Discussion}

Since the ancient times, aesthesia has been implemented through various methods such as chewing or topically using coca leaves, Cannabis sativa and similar plants or making the patients bleed until they are unconscious (3). Until the present day, thanks to developing technology and knowledge accumulation, peripheral blocks are spreading to very wide areas. The development of application techniques and the introduction of local anaesthetics into the practice have made positive contributions to this advance (4). On the condition that, adequate analgesia and optimal surgical conditions are provided, regional

Table 2. Demographic data of the groups

\begin{tabular}{llll}
\hline & BPB Group (n: 30) & GA Group (n: 30) & $\mathrm{p}$ \\
\hline Gender (M/F) & $16 / 14$ & $8 / 22$ & $\mathrm{p}=0.350$ \\
Age (year) \pm SD & $34.20 \pm 9.77$ & $35.50 \pm 7.57$ & $\mathrm{p}=0.567$ \\
Weight (kg) & $71.60 \pm 9.72$ & $70.40 \pm 9.04$ & $\mathrm{p}=0.622$ \\
Operation Duration (min) & $87.67 \pm 15.74$ & $95.50 \pm 24.64$ & $\mathrm{p}=0.147$ \\
ASA score (1/2) & $16 / 14$ & $11 / 19$ & $\mathrm{p}=0.194$ \\
\hline
\end{tabular}

BPB: Brachial plexus block GA: General anaesthesia SD: Standard deviation ASA: The American Society of Anaesthesiologists

Table 3. Cost values in the groups

\begin{tabular}{lllll}
\hline & TL (Mean \pm SD) & Min & Max & p \\
\cline { 1 - 3 } GA Group (n: 30) & $109.97 \pm 2.8$ & 103.86 & 115.19 & \\
BPB Group (n: 30) & $38.45 \pm 1.1$ & 37.45 & 39.75 & \multirow{2}{*}{0.001} \\
\cline { 1 - 3 } Total & $74.20 \pm 36.1$ & 37.45 & 115.19 & \\
\hline
\end{tabular}

TL: Turkish Lira

Table 4. Postoperative 0th min. VAS values of the groups

\begin{tabular}{lcccccc}
\hline & 0 & 1 & 2 & 3 & 4 & Total \\
\hline GA Group (n: 30) & 1 & 11 & 6 & 11 & 1 & 30 \\
BPB Group (n: 30) & 30 & 0 & 0 & 0 & 0 & 30 \\
\hline
\end{tabular}

Table 5. Comparison of the groups in terms of surgeon satisfaction

\begin{tabular}{lccccc}
\hline & 0 & 1 & 2 & Total & $\mathrm{p}$ \\
\hline GA group (n: 30) & 0 & 0 & 30 & 30 & \\
BPB group (n: 30) & 0 & 3 & 27 & 30 & 0.076 \\
\cline { 1 - 4 } Total & 0 & 3 & 57 & 60 & \\
\hline 0: not satisfied, 1: less than satisfied, 2: satisfied
\end{tabular}


Kahraman et al / Comparison of brachial plexus blockage with general anesthesia

Table 6. Intraoperative and post-operative complications

\begin{tabular}{lccc}
\hline & GA Group & BPB Group & Total \\
\hline No Complications & 18 & 27 & 45 \\
Hypotension & 4 & 0 & 4 \\
Nausea and vomiting & 3 & 0 & 3 \\
Agitation & 0 & 1 & 1 \\
Bleeding & 1 & 1 & 2 \\
Hypertension & 1 & 0 & 1 \\
Intraoperative pain & 0 & 1 & 1 \\
Bleeding and hypotension & 1 & 0 & 1 \\
Bradycardia & 1 & 0 & 1 \\
Tachycardia & 1 & 0 & 1 \\
\hline Total & $30(100 \%)$ & $30(100 \%)$ & $60(100 \%)$ \\
\hline
\end{tabular}

anaesthesia for any initiative is regarded as a more reliable way (2). In regional anaesthesia practices there are considerable advantages such as; patient vigilance, patient ability to say any complaints, continuation of spontaneous breathing, preservation of airway reflexes, maintenance of analgesia in the postoperative period and early mobilization of the patient (5).

Today, the use of ultrasound in Regional Anaesthesia is quite widespread. The studies have shown other advantages such as; lower doses of local anaesthetics in ultrasound guided block practices, increase of block success, lower complications rates, and less opioid consumption (5-7). Because of these advantages, in our study we preferred using ultrasound while applying BPB.

There are many scoring methods showing patient satisfaction score. One of the most widely used methods is Patient Satisfaction Scale. In the literature review conducted, when general anaesthesia and regional anaesthesia were compared, regional anaesthesia was found to be superior in terms of patient satisfaction. In the study conducted by Ozenc et al (8), patient satisfaction was found to be higher in patients who underwent regional anaesthesia than those who underwent general anaesthesia. Reasons behind this may be counted as the patient does not feel post-operative pain, lack of nausea and vomiting, and the ability to express any intraoperative problems in the early period. In our study, we have observed higher patient satisfaction in patients who underwent regional anaesthesia compared to the general anaesthesia group. In the study conducted by Soyarslan et al (9), no significant difference was found in terms of surgeon satisfaction between regional anaesthesia and general anaesthesia. In our study, there was no difference between the groups in terms of surgeon satisfaction.

In the study conducted by Gonano et al (10), hemodynamic instability was observed more in patients who underwent general anaesthesia compared to those who underwent brachial plexus blockage. In our study as well, in accordance with the literature, hemodynamic findings of $\mathrm{BPB}$ Group patients were more stable than general anaesthesia group patients.

In studies conducted by Chan et al (11), McCartney et al (12), regional anaesthesia was found to be more economical and to cause less postoperative complications compared to general anaesthesia. Pavlin et al (13), indicated that patients who were applied axillary brachial plexus block had shorter duration of stay at the hospital compared to the patients who underwent general anaesthesia. In our study, however, in terms of the duration of stay in the hospital, no statistically significant difference was found between the groups.

In a study conducted by Chan et al (11), it was claimed that in patients who would have elective hand surgery, implementation of regional anaesthesia caused less postoperative nausea and vomiting in comparison to general anaesthesia. In our study, there were three patients in the general anaesthesia group who had postoperative nausea and vomiting, while there weren't any in the regional anaesthesia group.

In the study conducted by Gonano et al (10), it was claimed that among the patients who would have shoulder arthroscopy, regional anaesthesia patients were more cost effective than general anaesthesia patients. It was shown that regional 
anaesthesia patients considerably reduced medicine consumption, anaesthesia control duration, and the stay duration in PACU. The total cost of general anaesthesia group was found to be 41, and cost of regional anaesthesia group was 33 Euro. But it was indicated, in case there is a failure in regional anaesthesia, general anaesthesia cost would be added on the top of block cost and the cost would go up to 55 Euros. In our study, while the GA group cost was 110 TL, the cost peripheral block applied group was 38 TL.

As a result; in upper extremity surgery, because brachial plexus blockage provides higher patient satisfaction, better VAS values in acute postoperative period, observation of lesser nausea and vomiting and is more economic compared to general anaesthesia, we believe, regional blocks must be used more often by being included in the routine practices.

Acknowledgment: We would like to thank Lokman Soyoral, MD. Asist. Prof., who helped collect and evaluate part of data in this study.

\section{References}

1. Kayhan Z. Local/Regional Anesthesia Methods: Clinical Anesthesia. 3. edition. Logos Publishing, İstanbul 2004; (in Turkish).

2. Hadzic's Peripheral Nerve Blocks and Anatomy for Ultrasound-Guided Regional Anesthesia 2. Edition. Mc Grew -Hill, 2012.

3. Morgan EG, Michael SM, Murray MJ. Lange Clinical Anesthesiology 2015.
4. Güldoğuş F, Gürkan Y. Regional Anesthesiology Nobel Medical Bookstore, 2013 (in Turkish).

5. Suresh S, Chan VW. Ultrasound guided transverses abdominis plane block in infants, children and adolescents: a simple procedural guidance for their performance. Paediatr Anaesth 2009; 19: 296-269.

6. Marhofer P, Harrop-Griffiths W, Kettner SC, Kirchmair L. Fifteen years of ultrasound guidance in regional anaesthesia: part 1. Br J Anaesth 2010; 104: 538-546.

7. Marhofer P, Frickey N. Ultrasonographic guidance in pediatric regional anesthesia Part 1: Theoretical background. Paediatr Anaesth. 2006; 16: 1008-1018.

8. Ozenc E, Comparison of general anesthesia with epidural anesthesia, which is a rare technique in lomber disc surgery, in terms of hemodynamics, patient comfort and cost. Haseki Teaching and Resarch Hospital İstanbul 2006 (in Turkish).

9. Soyarslan ÖD, Özlü Ö, Ütebey G, Er U. Comparing total intravenous anesthesia and spinal anesthesia in lumbar spinal surgery. Journal of Anesthesia - JARSS 2009; 17: 186-190.

10. Gonano C, Kettner SC, Ernstbrunner M, et al. Comparison of economical aspects of interscalene brachial plexus blockade and general anaesthesia for arthroscopic shoulder surgery. British Journal of Anaesthesia 2009; 103: 428-433.

11. Chan VW, Peng PW, Kaszas Z, et al. A comparative study of general anesthesia, intravenous regional anesthesia, and axillary block for outpatient hand surgery: Clinical outcome and cost analysis. Anesth Analg 2001; 93: 1181-1184.

12. McCartney CJ, Brull R, Chan VW, et al. Early but no long-term benefit of regional compared with general anesthesia for ambulatory hand surgery. Anesthesiology 2004; 101: 461-467.

13. Pavlin DJ, Rapp SE, Polissar NL, et al. Factors affecting discharge time in adult outpatients. Anesth Analg 1998; 87: 816-826. 